\title{
The nitrogen to creatinine ratio in untimed samples of urine as an index of protein catabolism after surgery
}

\author{
R. SWAMINATHAN \\ M.B., Ph.D \\ J. A. BRADleY \\ M.B., Ch.B. \\ G. H. HiLL \\ M.B., Ch.B., F.R.A.C.S. \\ D. B. Morgan \\ M.D., M.R.C.Path.
}

Departments of Chemical Pathology and Surgery, University of Leeds

\section{Summary}

The loss of nitrogen after surgery is said to be related to body size as well as to the magnitude of the metabolic effects of surgery. Urine nitrogen should be 'corrected' for body size before it can be taken as a guide to the severity of surgery in the individual. Twenty-three patients were studied after elective abdominal surgery of moderate severity, when they were having only 3 litres of dextrose saline daily. The 24-hr urine nitrogen excretion (mean of days 3 and 4) was correlated with 3 indices of body size, body weight $(r=0.614)$, fat-free mass $(r=0.743)$ and $24-\mathrm{hr}$ creatinine excretion $(r=0.780)$.

Nitrogen excretion was corrected for body size by calculating the ratio of nitrogen to each index. For each index the s.d. of this corrected nitrogen excretion at the mean value of the index was less than the s.d. of the uncorrected data. The nitrogen : creatinine ratio in an untimed urine sample was closely related to the ration in the 24-hr urine $(r=0.914)$. These results demonstrate that nitrogen excretion after surgery is related to body size and can be corrected for body size by calculating the nitrogen : creatinine ratio in an untimed urine.

\section{Introduction}

The loss of nitrogen which occurs in patients after surgery and trauma is thought to be an important determinant of their morbidity and mortality in these patients (Blackburn et al., 1973).

The loss of nitrogen increases with the severity of the event from elective surgery such as cholecystectomy through more major surgery such as rectal excision to major events such as gross sepsis and extensive burns (Kinney, 1967; Duke et al., 1970). These conclusions are based on comparisons of the average nitrogen excretion in groups of patients.

Most patients after surgery are not being given any nitrogen so that the urine nitrogen is the nitrogen loss if faecal loss is ignored, but even the urine nitrogen is unreliable in the individual because of difficulties in the collection of urine. The amount of nitrogen lost after a given surgical operation is said to be directly related to body size (Duke et al., 1970; Cuthbertson, 1964; Border, 1970; Moore and Ball, 1952; Abbott and Albertson, 1963; Dudrick and Duke, 1977), although this relationship has not been studied in detail (Richards, 1977). If this relationship exists then it might be that body size should be taker into account before the urine nitrogen can be take as a reliable guide to magnitude of the nitrogen los? in the individual. The amount of creatinine excreted. in the urine is related to body size (Forbes and Bruining, 1976), and it occurred to the authors that the simplest way of taking body size into account might be to calculate the ratio of nitrogen : creatinine in urine.

A further advantage of this ratio would be that it might be reliably estimated from an untimed sample of urine which would avoid the difficulties and error in the collection of 24-hr urines.

The authors have examined the relationships between urinary nitrogen excretion and 3 indices of body size in a group of patients after uncomplicated, moderately severe surgery. The 3 indices of body size were body weight, fat-free mass and urinary creatinine excretion. The relationship between the urinary nitrogen: creatinine ratio in untimed samples of urine and in 24-hr collections of urine was also examined.

\section{Patients}

Twenty-three surgical patients were studied after abdominal surgery of moderate severity, either vagotomy, cholecystectomy or hemicolectomy. All had an uncomplicated postoperative course. They were given 3 litres/day of $4.3 \%$ dextrose $(240 \mathrm{mmol} /$ 1) in $0.18 \%$ saline $(60 \mathrm{mmol} / \mathrm{l})$ intravenously for at least 5 days after operation. In all patients 24-hr urine collections were made for 5 days (noon to 
noon) beginning on the morning of the day of operation. In 6 of the 23 patients, a total of 14 untimed morning urine samples were collected as well as the 24-hr urine. This untimed morning urine was the first urine passed spontaneously after the overnight urine had been passed.

Untimed urine samples and 24-hr collections of urine were compared in other groups of patients. Twenty-nine patients were on an intensive care unit, because of severe trauma or postoperative complications and were having either no nitrogen intake or nitrogen intravenously at a constant rate. Fifteen patients were on a metabolic unit for the study of disorders of calcium metabolism or intestinal disease and were taking the same diet day by day.

\section{Measurement}

\section{The body composition}

The body composition of each surgical patient was assessed before operation. The height and weight of each patient were measured and at the same time the skin fold thicknesses over the biceps, triceps and subscapular were measured with a caliper. The fatfree mass (FFM) was calculated from the skin fold thickness and body weight according to Durnin and Womersley (1974).

The creatinine in urine was measured by the Jaffe reaction on a M300 Vickers multichannel analyser. The ammonia and urea in urine were measured also in a Vickers M300 multichannel analyser. The urea in the urine was converted to ammonia with urease, and the pre-existing and formed ammonia was measured by the Berthelot reaction. The sum of ammonia and urea content was taken as the nitrogen content of urine, i.e. the small amounts of other nitrogenous products, such as uric acid and amino acids were ignored.

\section{Results}

The urinary nitrogen excretion in the surgical patients was greatest on days 3 and 4 after operation and the average of the excretions on day 3 and 4 $[\mathrm{N}(3,4)]$ was taken as a measure of the rate of nitrogen loss in the individual.

Figure 1 shows the relation between $\mathrm{N}(3,4)$ and each of the 3 indices of body size. The correlation coefficients were highly significant in each case. Table 1 shows the residual variation of $\mathrm{N}(3,4)$ (as

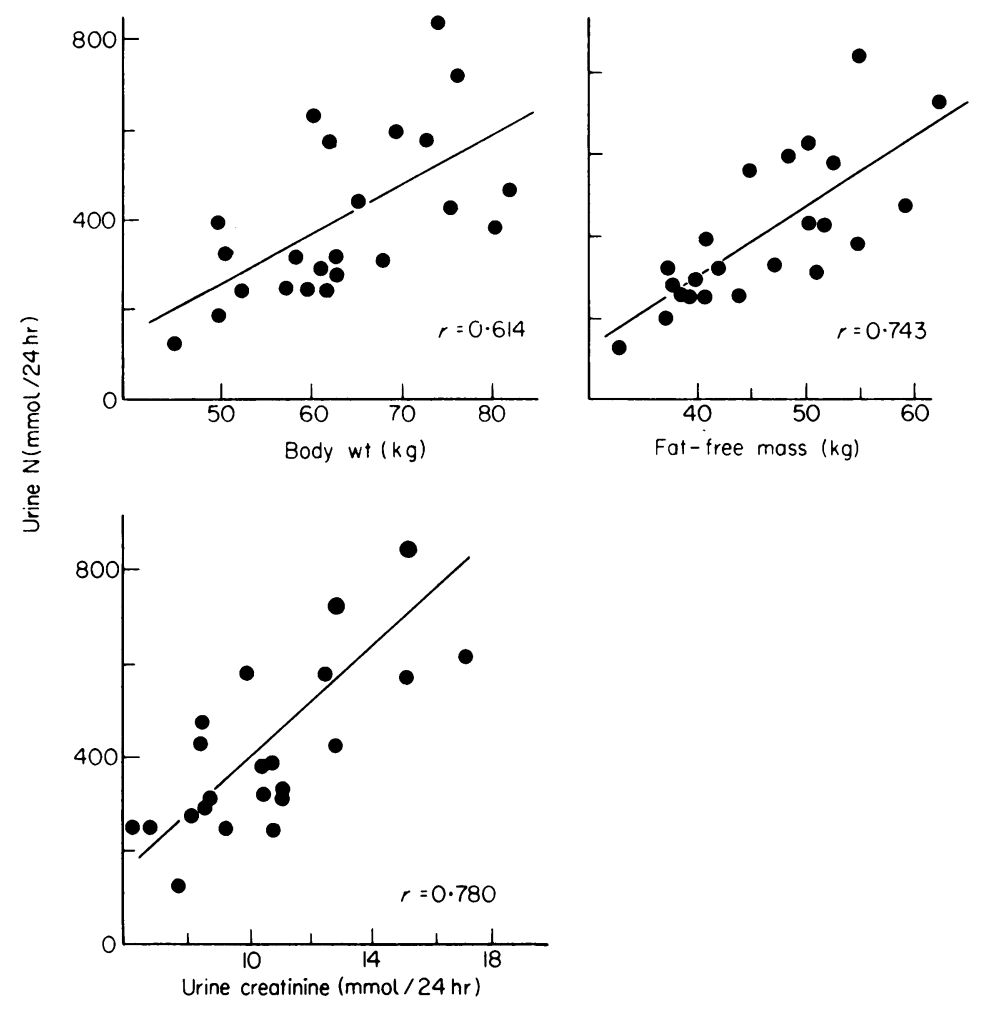

FIG. 1. The relationship between urine nitrogen excretion (mean of days 3 and 4) after surgery and (a) body weight; (b) fat-free mass; (c) 24-hr creatinine excretion. 
s.d.) after the regression on body size was taken into account. This residual s.d. is the standard deviation of the values about the regression line (Fig. 1). For each index of body size the residual s.d. was significantly less than the total s.d. and the reduction was greatest when $24-\mathrm{hr}$ creatinine excretion was the index of body size.

The $N(3,4)$ was also corrected for body size by calculating for each patient the ratio of $\mathrm{N}(3,4)$ to the index of body size. This ratio was multiplied by the mean value of each index to give the corrected value of $24-\mathrm{hr} \mathbf{N}(2)$. Table 1 shows that the standard deviation of this 'corrected' $\mathrm{N}(3,4)$ was less than the standard deviation of the uncorrected data, and that the reduction was greatest for the nitrogen: creatinine ratio. The standard deviation of the 'corrected' values was similar to the residual s.d. (Table 1).

TABLE 1. Correlation coefficient and standard deviation of nitrogen excretion corrected for various indices of body size by regression technique and by ratio method

\begin{tabular}{|c|c|c|c|c|c|}
\hline \multirow[b]{2}{*}{ Method } & & & \multicolumn{3}{|c|}{ Corrected for } \\
\hline & & & weight & FFM* & creatinine \\
\hline $\begin{array}{l}\text { Residual } \\
\text { Corrected }\end{array}$ & $\begin{array}{l}\text { s.d. } \\
\text { s.d. }\end{array}$ & $\begin{array}{l}180 \\
180\end{array}$ & $\begin{array}{l}145 \\
146\end{array}$ & $\begin{array}{l}123 \\
132\end{array}$ & $\begin{array}{l}115 \\
119\end{array}$ \\
\hline
\end{tabular}

*Fat-free mass

This analysis gives 2 estimates of the severity of nitrogen loss after injury in the individual after taking body size into account. These 2 estimates, the nitrogen:creatinine ratio in urine and the difference between the observed nitrogen excretion and that predicted from the creatinine excretion, were highly correlated in the 23 patients $(r=0.938)$.

Figure 2 shows that there was also a close relationship between the nitrogen : creatinine ratio in the untimed urine and that in the 24-hr urine ( $r=$ $0.914, P<0.001)$. This relationship is significant for the 3 groups.

\section{Discussion}

There is great concern with the nitrogen loss after surgery (Blackburn et al., 1973). This loss is usually measured as the loss of nitrogen or even urea in the urine (Lee, 1974). The amount of nitrogen lost is said to vary not only with the magnitude of surgical insult, but also with the sex, age and size of the patient (Cuthbertson, 1964; Moore and Ball, 1952; Abbott and Albertson, 1963). However, these relationships have not been studied in detail.

The present results demonstrate that the nitrogen loss on the third and fourth day after surgery of moderate severity is related to body size as assessed by body weight, fat-free mass or urinary creatinine excretion. The closest relationship was with the urinary creatinine which suggests that muscle mass is the component of body size which determines the nitrogen.

These relationships are of biological interest but the question arises as to whether it is feasible, and worth-while to take them into account in practice. In the comparison of groups of patients the problem can be avoided by carefully matching the groups in age, sex, weight and even fat-free mass (Craig et al., 1977).

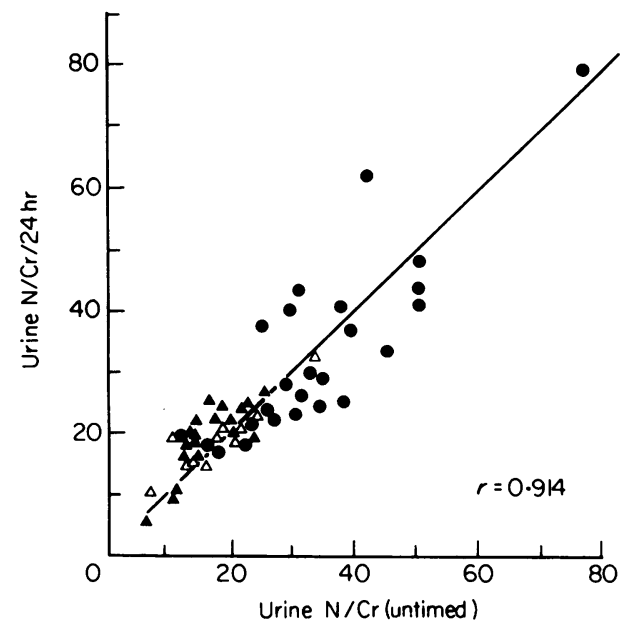

Fig. 2. The relationship between urine nitrogen creatin- $\overrightarrow{0} \overrightarrow{0}$ ine ratio in untimed urine sample to that in the 24-hr urine in postoperative patients $(\triangle)$, patients in intensive care not eating $(\odot)$ and patients in a metabolic ward taking a constant diet $(\Delta)$.

The application of these observations to the assessment and management of the individual patient depends on what is required. If what is wanted is an index of the severity of nitrogen loss in the individual then body size should be taken into account and this can best be done by calculating the nitrogen: creatinine ratio in urine. All that is required is an untimed sample of urine, so that the difficult task of obtaining accurate 24-hr collections of urine is avoided, and the information could be available on the wards the same day rather than a day later. The present results suggest that an untimed urine can be used even when the patient is being given nitrogen.

On the other hand, the nitrogen : creatinine ratio is not satisfactory if what is required is an indication of nitrogen loss and nitrogen balance. The direct $\overline{\bar{N}}$ measurement of 24-hr urinary excretion of nitrogen or is difficult in practice, particularly in postoperative $N$ patients. An estimate of 24-hr urinary nitrogen could $\underset{\omega}{N}$ be obtained by multiplying the nitrogen : creatinine 0 ratio in the untimed specimen by the average 24-hr 0 creatinine for men or women as appropriate. A $\stackrel{\mathbb{D}}{\overparen{D}}$ compromise would be to measure the $24-\mathrm{hr}$ ex- $\stackrel{\mathcal{Q}}{?}$ cretion of creatinine before operation and multiply 
the daily nitrogen:creatinine ratio in untimed urine samples after operation by this value to give estimates of the 24-hr excretion of nitrogen. Studies are in progress to assess these approaches.

\section{Acknowledgments}

We would like to thank Mrs A. Newill and Mrs J. Stevens for technical help and the nursing staff of wards 27 and 28 for their co-operation.

\section{References}

Abbott, W.E. \& Albertson, K. (1963) The effect of starvation, infection and injury on the metabolic processes and body composition. Annals of the New York Academy of Science, 110, 941.

Blackburn, G.L., Flatt, J.P., Clowes, G.H.A., O’DonNELL, T.F. \& Hensle, T.E. (1973) Protein-sparing therapy during periods of starvation with sepsis or trauma. Annals of Surgery, 177, 588.

BORDER, J.R. (1970) Metabolic response to short-term starvation, sepsis and trauma. Surgery Annual, 2, 11.

Craig, R.P., Davidson, H.A., Tweedle, D. \& Johnston, I.D.A. (1977) Intravenous glucose, aminoacids, and fat in the postoperative period. A controlled evaluation of each substrate. Lancet, ii, 8.

Cuthbertson, D.P. (1964) In: Mammalian Protein Metabolism p. 373, Academic Press, New York.

DUDRICK, S.J. \& DUKE, J.H. (1977) Nutritional complications in the surgical patient. In; Rhoads' Textbook of Surgery: Principles and Practice. 5th edn. p. 243, Lippincott, Philadelphia.

Duke, J.H., Jørgensen, S.B., Broell, J.R., Long, C.L. \& KINNEY, J.M. (1970) Contribution of protein to caloric expenditure following injury. Surgery, 68, 168.

DuRnIN, J.V.G.A. \& WomersLeY, J. (1974) Body fat assessed from total body density and its estimation from skinfold thickness: measurements on 481 men and women aged from 16 to 72 years. British Journal of Nutrition, 32, 77.

FoRBES, G.B. \& BRUINING, G.J. (1976) Urinary creatinine excretion and lean body mass. American Journal of Clinical Nutrition, 29, 1359.

KINNEY, J.M. (1967) The effect of injury on metabolism. British Journal of Surgery, 54, (Suppl.), 435.

LEE, H. (1974) In: Parenteral Nutrition in Acute Metabolic Illness p. 307, Academic Press, London.

MoORE, F.D. \& BALL, M.R. (1952) In: The Metabolic Response to Injury. Charles C. Thomas, Springfield, Illinois.

RicHARDS, J.R. (1977) In: Nutritional Aspects of Care in the Critically Ill, p. 273. Churchill Livingstone, Edinburgh. 